\title{
Глоттодидактические аспекты кросскультурного образования и коммуникации
}

\begin{abstract}
In the introductory remarks the author emphasises that intercultural education through the foreign language correlates not only with the basic assumptions of modernising the teaching/learning of foreign languages, put forward by the Council of Europe, but most of all with the humanistic aspects of the teaching content, which should aim at shaping the homo moralis and homo communicus. The following general determinants are distinguished in the exploration of the problem: cognitive, psychological, didactic-sociocultural and pedagogical. Then the author characterises in detail the socalled base determinants, i.e. the intercultural and linguistic-cultural competencies, and discusses the factors determining the shaping of these competencies.
\end{abstract}

Научные дисциплины гуманитарного профиля в своих исследовательских поисках последнего десятилетия ставят два фундаментальных вопроса: во-первых - стремление к глубокой специализации в определенных отраслях (как результат открытия новых аспектов, требующих более глубокого и всестороннего их познания и осмысления адекватными средствами), во-вторых - стремление найти комплексные средства изучения явлений, многосторонность которых раскрывается в процессе эволюции научных дисциплин. Второй вопрос характеризуется тем, что имеет интердисциплинарный характер. Его суть сводится, между прочим, к переходу от моно- к би- и мультикультурности и находит свое отражение во многих научных дисциплинах (напр.: культурологии и лингвокультуролюгии, этнологии и этнолингвистике, линвистике и прагмалингвистике, психологии и психолингвистике, социологии и социолингвистике, дидактике и глоттодидактике). 
Вторую проблему в общем плане можно выразить следующим образом: „на наших глазах рождается н о в а я (разрядка наша. - Т.Р.) цивилизация, независимо от того, какой нации касается ее эволюция, когда мир стал более открытым, а процессы глобализации, интеграции и унификации перед нами налицо, становятся абсолютной потребностью не только эффективность экономики, но и взаимопроникновение культур, осознание своеобразия каждой из них, постижение духовных особенностей отдельных народов" (Markunas, 2002 : 18).

Данное утверждение, особенно его последнюю часть, можно считать в какой-то степени представительным - общим обосновагием главной цели нашей статьи, т. е. обсуждения многоаспектных вопросов кросскультурного образования и коммуникации.

Следует подчеркнуть, что представленные в данной публикации вопросы являются продолжением, в более углубленном смысле, той коншепции автора, которая была только намечена в одной из последних его статей (Pacholczyk T., 2005: 111-115).

В самом начале рассмотрения поставленных вопросов считаем целесообразным внести некоторое уточнение в понятийном отношении. В ходе дальнейшего освещения указанных ранее проблем всякий раз, когда будет идти речь о кросскультурном образовании и коммуникации, будем иметь в виду прежде всего то, что они осуществляются с помощью родного, иностранного или нескольких инострапных языков, одлгко чаще всего с учетом их сопоставления.

В последнее десятилетие (рубеж XX и XXI веков) особое место во многих исследовательских поисках (см., напр.: материалыы VIII, IX и X конгрессов МАПРЯЛ $(1994,1999,2003)$ уделялось и в далыгйшем уделяется вопросам ^ингвокультурологии и, в меньшей степени, ее глоттодидактическим импликациям. На основании этих поисков можно сформулировать общий тезис - одно из самых важных направлений в модернизации как теоретической, так и прикладной глоттодидактики касается интеркультурного образования. Этот тезис созвучен с основными положениями модернизации обучения/учения инострағным языкам, выдвинутыми в свое время Советом Европы.

Нужно отметить, что в основе этой модернизации лежит европроект Изучение языков для общеевропейского гражданства. В нем главное положение касается социокультурного образования с помощью иностранного языка и построение глоттодидактического процесса на интердисциплинарной культуроведческой и лингвокультуроведческой основе с учетом коммуникативного направлегия (Сафонова, 1997). Осуществлгение этого положения должно способствовать развитию когнитивного потенциала учащихся и формированию их аккомодационных способностей нахождения своего места в многоэтнической Европе, которая 
во все большей степени проявляет интегрирующий характер во многих областях современности.

Основополагающей предпосылкой, обосновывающей указанный ранее тезис, можно считать то, что интеркультурное образование с помощью иностранного языка и вытекающие отсюда базисные культуроведиеские иели вполне совпадают не только с основными положениями модернизации обучения/учения иностранным языкам - как указывалось выше, но прежде всего с гуманитарным аспектом содержания образования, которое должно быть направлено на формирование человека духовного - homo moralis и общающегося - homo communicus. Первому свойственны духовные ценности прежде всего культуроведческого или лиинвокультуроведческого характера. В свою очередь, для второго - homo communicus - характерно то, что его следовало бы рассматривать как субъект, не только адекватно воспринимающий данную этническую культуру посредством языка, но и как языковую личность, как носителя и творца сверхличных ценностей.

Общеизвестно, что как в теоретической, так и прикладной глоттодидактике очень важное место занимают цели и содержание обучения. Следует подчеркнуть, что эти два компопента существенным образом могут повлиять на эффективность глоттодидактического прошесса, если они точно и однозначно определены, между прочим, в рационально разработанной таксономии целей. Авторы многих программ обучения в области иностранных языков подчеркивают, что основной целью обучения является формирование речевых навыков и умений, в конечном итоге - сформированность лингвистической и коммуникативной компетенций, или в идеальном варианте - глобальной коммуникативной компетенции, как конечного результата реализации целей. Однако если учесть, что основной целью образования является передача культуры, точпее постижение и осмысление культурных ценностей - артефактов, то иноязычное образование можно рассматривать как передачу иноязычной культуры (см., напр.: Пассов, 2000: 37). В таком понимании цель существенным образом должна определять содержание обучения иностранному языку.

В свете сказанного выше можно констатировать, что цель и содержание интегрально связаны друг с другом. Другими словами, содержание должно быть адекватно цели.

Следует, однако, отметить, что содержание как иноязычного межкультурного образования, так и кросскультурной коммуникации, составляющей интегральную часть этого образования, значительно шире и многоаспектнее, чем это традіиционно представляется.

Образование обычно рассматривается как процесс и результат усвоения знаний, навыков и умений. В основе этого усвоегія всегда ле- 
жит познание, которое интерпретируется как высшая форма отражения действительности, которое проявляется на сенсорном, интеллектуальном, эмпирически-прикладном и теоретическом уровнях. Однако если учесть, что практическая деятельность и речевая коммуникация образуют единство, то познание значительно шире, чем усвоение языковых знаний, сформированность речевых навыков и умений.

В свою очередь, образование - это количественные и качественные преобразования психики, рассматриваемые в прогрессирующем контексте. Это происходит только тогда, когда человек является субъектом речевой коммуникации, рационально воспринимающим духовные ценности культуры данного этноса через призму как современности, так и в историческом аспекте.

В дальнейшем образование включает в себя воспитание, рассматриваемое не только как формирование личности, но и как процесс постижения широко понимаемой общественной культуры, в том числе прежде всего иноэтнической.

Наконец, образование содержит дидактический аспект, который можно рассматривать как овладение рецептивными и продуктивными видами речевой деятельности, в основе которых лежат аспекты языка (произношение, лексика и грамматика).

Таким образом, иноязычное образовапие включает в себя:

- познание, которое направлено на овладение культурологическим содержанием иноязычной культуры;

- развитие, которое нацелено на овладение психологическим содержанием культуры иноэтноса;

- учение (дидактический аспект), которое находит свое отражение в овладении социальным содержанием иноэтноса;

- воспитание, которое направлено на педагогический аспект содержания данной иноязычной культуры (этические ценности) [ср., напр.: Пассов, 2000: 39].

Подытоживая вышесказанное, можно прийти к выводу, что при определении и отборе содержания, направленного на формировапие иптеркультурной коммуникации в рамках кросскультурного образования, нужно учесть следующие обусловленностк:

- когнитивную;

- психологическую (развивающую личность);

- дидактически-социокультуриую;

- педагогическую (воспитательную).

Эти четыре взаимосвязанных и взаимообусловленных концепта следовало бы условно рассматривать как общие детерминанты инокультурного образования и коммуникации. Кроме этих детерминант может идти речь о более детальных, которые непосредственно касаются ино- 
странного языка. Следует подчеркнуть, что они фактически могут функционировать на фоне intercultural communication. С этой целью считаем целесообразным дать в сжатом контексте характеристику интеркультурной коммуникации. Это поможет нам рационально, с нашей точки зрения, обсудить те детерминанты, которые касаются иностранного языка в контексте кросскультурной коммуникации и определить некоторые глоттодидактические импликации.

В рамках интеркультурной коммуникации исследуются, между прочим, вопросы коммуникативного поведения и рече-поведенческие тактики (напр.: Milton J. Bennett 1998; Larry A. Samovar, Richard E. Porter 1995; Верещагин Е.М., Костомаров В.Г. 1990; Прохоров Ю.Е. 1997; Красных В.В., Изотов А.И. (ред.) 1997; Гудков Д.В. 2003; Тер-Минасова С.Г. 2000; Формановская Н.И. 2002).

С этой сравнительно новой научной дисциплиной интегралььно связаны интеркультурная и лингвокультурологическая компетеници, которые, по сути дела, можно считать базисными детерминантами кросскультурной коммуникации, кроме общих, представленных ранее. Эти две детерминанты также неразрывно связаны с вопросами обучения/учения иностранным языкам, если учесть, что основной целью в аквизиции иностранного языка является общение на этом языке с учетом культуроведческого компонента.

Перечисленные выше базисные детерминанты вмещаются в русло лингвокультуроведения, которое обычно рассматривается (последнее десятилетие) как отдельный предмет филологического образования. Его сущность сводится к тому, что оно содержит совокупность сведегий о культуре страны изучаемого языка, необходимых для осуществления речевого общения на этом языке. Эти сведения способствуют реализации различных целей: образовательных, когнитивных, прагматически-коммуникативно-речевых, воспитательных и интеллектуальных.

Исходной предпосылкой, обосновывающей лингвокультуроведение, можно считать утверждение, согласно которому как лингвокультуроведение, так и лингъокультуроведческая парадигма современной глоттодидактики (пока рождается) основываюгся на социальной природе языка, его коммуникативном предназначении и социализации языковой личности. В этом контексте можно выдвинуть предложение сугубо прикладного характера. Его цель - включить инокультурного учащегося в инокультурную коммуникацию (см. шире: Pacholczyk 2002: 151-155).

В основе intercultural communication, в принципе, лежат две базисные детерминанты, о которых мы упомянули ранее, т.е. интеркультурная и лингвокультурологическая компетениии. Эти две детерминанты были предметом нашего детального рассмотрения в контексте более общего 
вопроса, т.е. глобальной коммуникативной компетенщии (см. шире: Раcholczyk 2002: 287-292). Исходя из этого, ограничимся только представлением их как понятий, в свое время выдвигаемых и интерпретированных нами. С другой стороны, это ограничение обуслювлено тем, что во многих работах данные коншепты интерпретировагы по-разному.

Лингвокультурологическая компетенция рассматривается как система знаний о культуре, воплощенная в определенном национальном языке. Обсуждая подробно этот своеобразный вид компетенции, мы пришли к выводу, что „сфера знаний, связанная с содержанием информации о культуре с постигаемыми смыслами и ценностями, содержащимися в отдельных феноменах культуры, составляет лингвокультуроведческую компетенцию" (выделено автором статьи) (Woźniewicz, 2000: 19).

В основе межкультурной компетенции находится осознание различий и сходств интеркультурного характера, выступающих между родной и иноэтнической культурой, нашедшей, в частности, выражение в лексико-семантических единицах родного и иностранного языков (Раcholczyk, 1998: 202).

В свете сказанного выше, особенно в контексте гуманитарного содержания обучения, которое должно учитывать реляции: отечественная культура - иноэтническая культура (они, как известно, находят свое отражение как в рамках родного, так и изучаемого иностранного языка), вырисовываются следующие базисные культуроведческие изели (точнее умения), которые были акцентированы нами уже ранее:

- умение замечать сходства и различия между отечественной культурой и культурой нации (этноса), язык которой является предметом обучения;

- умение смотреть на людей и различные их проблемы глазами носителей другой культуры и понимать их точку зрения;

- стремление к объективизации образа отечественной культуры с целью получения рационального образа этой культуры, обычаев, традиций и способов мышления (т.е. менталитета);

- умение справляться с межкультурными недоразумениями и этническими конфликтами в случае их возникновения (см., напр.: Komorowska, 1996: 112).

В контексте этих целей (умений) нужно, однако, отметить, что „каждый язык и каждая культтра должны сохранять свой неповторимый цвет в общемировой культурной палитре" (Вербицкая, 2001: 2).

Перечисленные ранее цели должны быть направлены на формирование лингвокультуроведческой и интеркультурной коммуникативных компетенций, и только в таком случае могут выполнить свое назначение [они вмещаются в русло широко понимаемого социокульттурного и ме- 
жкультурного общения (ср., напр.: Митрофанова (ред.), 1996: 15-16; Прохоров 1998)]. Интеркультурную коммуникативную компетенцию рассматриваем как субкомпетенцию глобальной иноязычной коммуникативной компетенции.

Следует, однако, в этом контексте сделать одно существенное замечание. Вопрос касается определения общих положений, детерминирующих сформированность лингвокультуроведческой и кросскультурной коммуникативной компетенций.

По нашему глубокому убеждению, существует возможность сформировать лингвокультуроведческую и интеркультурную компетенции в рационально организованном глоттодидактическом процессе, если у изучающих иностранный язык есть:

- необходимые, хотя бы основные культурологические знапия общего характера, в том числе сформированные прежде всего на родном языке, но касающиеся элементарных вопросов как общей, так и прикладной культурологии (например: основные черты эпохи Возрождения и Ренессанса, христианство и европейская цивилизация, феномен иконы в православной Церкви и т.д.);

- основные языковые средства, необходимые для выражения речевых интенций, позволяющих вступать в речевой акт (папример, формы речевого этикета - приветствие, прощание и т.д.);

- элементарные рецептивные и продуктивные виды речевой деятельности на изучаемом иностранном языке (т.е. на уровне основного курса данного языка);

- необходимые навыки переноса (трансфера), особенно продуктивных видов речевой деятельности (ср., напр.: Прохорова 2001: 37).

Сказанное выше не означает, что существует возможность сформирования лингвокультуроведческой и кросскультурной компетенций и с к л ю ч и т е л ь н о с учетом перечисленных положений. Они могут только повлиять на более эффективную их выработку. В принципе эти полюжения должны найти свое отражение уже с самого раннего периода обучения иностранному языку, т.е. в рамках начального этапа, а затем на высших уровнях (этапах) они осложняются и расширяются (концентризм в обучении).

Рассматриваемые нами вопросы кросскультурного образования $и$ коммуникации имплицируют обсуждение следующих проблем, которые можно считать также своего рода детерминантами, обусловливающими эффективность и рациональность указанного выше образования и коммуникации. К ним, в частности, относятся:

1. изучение специфики отражения национальной культуры как проявления национального менталитета, находящего свое выра- 
жение в языке, с учетом моноактивных, полиактивных и реактивных культур;

2. рациональное установление принципов описания, отбора и изучения единиц культурного знания дця дидактических целей с учетом кросскультурных адапторов (понятие кросскультурного адаптора интерпретируем как способ овладения компетенцией интеркультурной коммуникации, направленной на повышение межкультурной сензитивности, смягчающий последствия культурного шока и учитывающий двусторонний процесс взаимодействия коммуникантов (ср.: Кузнецова 2003: 100);

3. разработка прикладного изучения и приобретения культурных знаний при постоянном сопоставлении родного и иностранного языков;

4. лингвокультуроведческий сравнительный анализ программных основ и программ обучения в области всех предметов гуманитарного профиля в польской системе народного образования (напр.: история, польский язык, география и т.д.), - нам кажется, что не только в польской; основная цель - модернизация программ обучения;

5. лингвокультуроведческий сравнительный анализ программных основ в области пяти самых популярных иностранных языков в польской системе народного образования: английский, немецкий, русский, французский, испанский (очередность перечисленных языков не случайна - они представлены иерархично в зависимости от их популярности в Польше); основная цель - модернизация программ обучения;

6. лингвокультуроведческий сравнительный анализ иностранных языков, представленных выше, в области программ обучения; основная цель - модернизация этих программ;

7. лингвокультуроведческий сравнительный анализ программ обучения в области русского языка в контексте сопоставления с другими иностранными языками (п. 5); основная цель - модернизация обучения русскому языку.

Указанные выше детерминанты (по всей вероятности, их может быть больше) в принципе можно считать отдельными исследовательскими вопросами, которые требуют еще детального научного обсуждения и освещения, прежде всего в эмпирическом плане.

Представленные и проанализированные в данной публикации обусловленности составляют попытку комплексно рассмотреть и по-новому осмыслить многоаспектные вопросы кросскультурного образования и коммуникации, прежде всего в глоттодидактическом плане. 


\section{ПРИМЕЧАНИЯ}

Markunas A., 2002, Стереотипность как концептосфера в русском языке, литературе, культуре и греподавағии русского языка, в: Studia Rossica Posnaniensia, vol. XXX.

Pacholczyk T., 2005, Иіттеркультурное образование - его детермиганты и глоттодидактические импликации (попьтка опредетения), в: „Новое 6 теории и практике описания и преподавания русского языка", Warszawa.

Материалы VIII Конгресса МАПРЯЛ. Русский язык и литература 6 современном диалоге культур (тезисы докладов). (1994). Регенсбург; Материалы Конгресса МАПРЯЛ. Русский язык, литература и культура на рубеже веков. (1999). Москва, (доклады-статьи: В.Н. Белоусова [с. 51-69], Л.А. Вербищкой [с. 93-96], В.В. Воробьева [с. 96-118], В.Г. Костомарова и Н.Д. Бурвиковой [с. 252-261], В.В. Красных [с. 266-272], А.Л. Кузнецова [с. 272-274], А.Д. Летовой [с. 332-334], О.Д. Митрофановой [с. 345-364], Е.И. Пассова [с. 422-440], Ю.Е. Прохорова [с. 450-465], Р.Б. Сабаткоева [с. 471-474], Л.Г. Саяховой [c. 474-477], В.М. Шаклеина [с. 503-515]); Материалы Х Конгресса МАПРЯЛ. Русское слово в мировой культуре. (2003). Санкт-Петербург, Национально-культурная специфика речевого поведения и проблемы обучения русскому языку как иностранному, т. I, (разд. I, c. 8-208).

Сафонова В.В., 1997, Иностранный язык в двуязычном образовании российских студегтов, в: Ииостранные языки В иколе 1.

Пассов Е.И., 2000, Коммуникативное иноязычное образование. Концепция развития индивидуальности 6 диалоге культур, Липецк.

Bennett Milton J., 1998, Basic concepts of Intercultural Communication: Selected Readings; Larry A. Samovar, Richard E. Porter (1995). Communication between cultures, $2^{\text {nd }}$ ed.; Верещагин E.M., Костомаров В.Г. (1990). Язык и культура. Лингвострановедение В преподаВании русского языка как иностранного, Москва; Прохоров Ю.Е. (1997). Национальные социокультурные стереотипы речевого общения и их роль в обучении русскому языку иностранцев, Москва; Красньгх В.В., Изотов А.И. (ред.) (1997). Лингвокогнитивные проблемы межкультурной коммуникации, Москва; Воробьев В.В. (1996). Лингвокультурологическая парадигма цичности, Москва; Гудков Д.Б. (2003). Теория и практика межкультурной коммуникации, Москва; Тер-Минасова С.Г. (2000). Язык и межкультурная коммуникация, Москва; Формановская Н.И. (2002). Речевое общение : коммуникативно-прагматический подход, Москва и другие.

Pacholczyk T., 2002, О лингвокультуроведческой парадигме современной глоттодидактики - попытка определения (на материале русского языка как иностранного), Studia Rossica Posnaniensia, vol. XXX.

Pacholczyk T., 2002, Глобальная коммуникативная компетенция в контексте лингвокультуроведческой парадигмы современной глоттодидактики, в: Новое 6 теории и практике описания и преподавания русского языка (материалы IX Международной конференции, проходивщей 16-17 мая 2002 г. в Варшаве), Warszawa.

Woźniewicz W., 2000, Лингвокультурологическая компетенция как составляющая глобальнои языковои компетенции иноэтницеского филолога-русиста, в: Актуальные вопросы языкового, культуроведиеского и лингводидактического образования студентов русистики, под ред. Я. Генцеля, Kraków.

Pacholczyk T., 1998, Роль и место интеркультурной компегенции в теоретической и прикладной глоттодидактике, в: Studia Rossica Posnaniensia, vol. XXVIII.

Пороговой уровень. Русский язык. т. I, Повседневное общение (1996), под ред. О.Д. Митрофановои, Совет Европы Пресс.

Прохоров Ю.Е., 1998, Лингвострановедение. Культуроведение. Страноведение, Москва.

Komorowska H., 1996, Nowe tendencje w pracach programowych Rady Europy. Koncepcja celów nauczania języków obcych. In : Języki Obce w Szkole nr 2. 
Вербицкая Л.А., 2001, МАПРЯЛ на пуги в Петербург, в: Русский язык за рубежом 1.

Прохорова И.О., 2001, Формирование лиигвокультурологической компетенции на занятиях по русскому языку, Русский язык за рубежом 3.

Кузнецова ОЛ., 2003, Методические аспекты межкуньтурной коммуникации, в: „Русское слово В мировой кульптре" - Х Международный Конгресс МАПРЯЛ, Санкт-Петербург. 